\title{
Constructing Combined Courses System of Operations Research and Information Technology: A Way to Practice "New Business Studies"
}

\author{
Sheng Zhang, Hang Su , Yi Luo, Lingjing Duan \\ School of Management, Guizhou University of Commerce, Guiyang 550014, China \\ *Corresponding Author: Sheng Zhang Email: zhangsheng85@hotmail.com
}

\begin{abstract}
Since the development of artificial intelligence (AI) and big data has changed the traditional business model, business school students are facing more challenges in these days. They should master inter-disciplinary skills both in IT and OR to keep competitive in career market. It is also an opportunity for business school to combine OR and IT courses in order to revise the traditional course structure in business school. In order to discuss the possibility and necessity of OR and IT combined course system in business school, firstly we review the development of OR courses system. Then we discuss the structure design and curriculum relationship of OR and OR related course systems. After the discussion, we study the reconcile of IT and OR courses that meets different requirement of students' IT ability. Finally, we make a case study of teaching practice at Guizhou University of Commerce to discuss the effect of OR and IT combined courses system and how this system meets the need of "new business studies".
\end{abstract}

Keywords: operations research, information technology, new business studies, courses system

\section{INTRODUCTION}

In era of big data, OR can be an instrumental tool to solve quantitative problems in business such as operations and supply chain management[1]. Gupta et al [2] discussed a framework of model curriculum for business school undergraduates, MS Graduates, and MBAs. to satisfy the need of talents in data analysis. In this point, OR and IT combined courses system can be an efficient solution for improving students' IT application and quantitative analysis ability. However, in many universities, OR courses, especially OR related experiments, are still guided by the systems of business simulations provided by Larréché[3], which should be revised and redefined to meet the challenges and opportunities of the big data era. Johnes [4] examines the typical models that can be useful to develop the quantitative capacity in diverse problems faced by different kinds of careers. So, it is important to discuss how to revise the traditional OR course in business education, which can be dated from 1959 [5].

The discussion of how to teach OR in microcomputers dates from 1985 [6], and still continues recently [7]. Dias [8] discusses the importance and necessity of gamification in operations research teaching.

However, few scholars merge how to improve the undergraduates' both quantitative and IT capacity in OR related courses. In this paper, we firstly discuss the necessity of OR teaching with IT-assisted tools, then we provide ways and teaching method of how to reform the traditional OR related courses to more interesting and employment-oriented course systems.

\section{THE CURRICULUM DESIGN OF OPERATIONS RESEARCH COURSES SYSTEM}

OR courses system with IT-assisted tools consists basis courses, OR related course, IT related course and combined experimental courses of OR and IT-assisted tools.

\subsection{Basic courses}

OR related basic courses includes management, higher mathematics, linear algebra, probability theory and mathematical statistics, and microeconomics, which are all traditional general basic courses in undergraduate basic course of China.

Management provides the training of undergraduates' skills to plan, organize, lead, and control in practice and theory. So the undergraduates can understand the importance of planning and organizing in an organization. When qualitative tools of management cannot be applied to certain problems, students will be interested in finding news methods about modelling and optimizing, which finally lead students to study OR.

Mathematics courses, including higher mathematics, probability theory and mathematical statistics, and linear algebra are the bases of training quantitative skills. In the course of $\mathrm{OR}$, all contents are related to mathematics. i.e. linear programming is closely related to linear algebra, and queuing theory can be seemed as application of probability theory and mathematical statistics, and stochastic process. 
If business undergraduates studie all the mathematics mentioned above, OR related courses can lead them build application ability of such mathematical theory and tools. Microeconomics is also crucial for the study of OR. This course can cultivate students the thoughts of hypothesis of economic man, and subsequently know the ways of economic optimization. If business undergraduates study microeconomics well, they will have few obstacles to comprehend the theory of linear optimization and some important OR ideas such as duality theory and shadow price.

All those basic courses are useful for the study of OR, and provide basic skills training for students to lay a good foundation for continuous OR related courses.

\subsection{OR courses group}

In China, many undergraduate business education provides OR course or OR related courses such as linear planning, theory of optimization and management science. These courses are closely related to OR. However, many other courses in business school, like computer application in economics and management, experiment of optimization, operations management, prediction and decision making, requires that the students have the basic skills of OR more or less. So if we consider the potential combination of these courses, we can construct an OR course system, an OR course group. We divide the courses of OR course group into three types: operations research, which is the core of the course group, OR related experiment course and application course of OR skills.

Operations Research or its similar course is the core and basic course. In business school, OR course mainly provides chapters containing linear programming and its sensitivity analysis, transportation problems, goal programming, integer programming, theory of graph, queuing theory and storage theory, where most of them are parts of linear programming. However, considering how to apply OR skills in the future, we provide stochastic optimization course such as queuing theory and storage theory. OR course is very important for the construction of modelling and optimizing skills for students of business school, not only because it gives students the theoretical basis of quantitative analysis, but also makes students know how to solve problems in a more verifiable approach. About the OR course's time allocation, we put more effort in modelling and solution method. Although challenge to the importance of solution method is discussed widely, which often emphasize the application of optimizing software, we think that solution method are very important for students' improvement of computing power and deep understanding of model itself. So teaching team of OR course in our school allocate relatively more time in teaching solutions method such as simplex method, Vogel method, and Hungarian algorithm.

OR related experiment courses focus on the training of students' application skills of OR using several IT based software. Once the students construct their OR model, they can income the data of model into systems and soon get the data outcome of the optimization problems. The related software which we apply includes LINDO, EXCEL and Managements Operations Research 3.0. For undergraduate students, we rarely ask students to improve algorithm, however, some students can design or improve algorithm using MATLAB or Python. This provide the teaching team more pressure to consider the transition of different courses.

Application course of OR skills includes all follow-up courses that relate to application of OR. The major of management science in business school provide courses such as project management, prediction and decision making, multivariate statistics, systems engineering and graduation thesis. These courses are more or less related to OR, and basic knowledge of OR can be useful to students in business school for further study.

So if we see all those courses as a group, we can explain their relationship as Fig.1. OR or its similar course is at the center. Basic courses provide fundamental mathematical knowledge to OR, and OR can contribute to further study of OR related courses. However, OR courses group itself does not provide sufficient training for students to grasp competitive power in the field of IT, so that they can not follow the new era of big data and AI and thus does not meet the need of "new business studies".

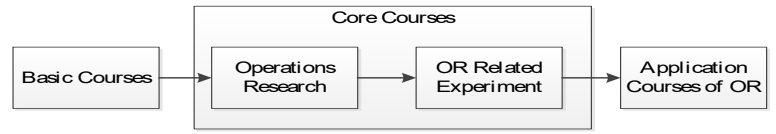

Figure 1 Relationship of OR related courses

However, OR courses group, as an important tool of quantitative analysis, cannot be applied to future study and work for students, if these course systems were not combined to information technologies. So it is more challenging for teachers to consider the combination of OR courses and IT courses. This kind of courses, commonly named as computer application in economics and managements, includes basic application (DQL) of database, data processing and data perspective, modelling and analysis, and data stimulation. In the perspective of comprehensive application, this kind of experiment require students to master basic knowledge of statistics, database principles, operational research and financial management, so students should learn to solve interdisciplinary problems.

\section{COMBINATION OF OR AND IT COURSES}

The curriculum design of business major, unlike that of engineering major, should not be focused on IT-related courses, but for their future development, the study of ITrelated course is important for application of theory courses. So if we can combine the OR courses to IT courses in an efficient way, we will improve students' application ability in both work and future study. For business school, undergraduate students are not commonly 
required to study programming language, so it is difficult for teachers to teach courses using professional modeling software such as MATLAB. So how to use limited choices to improve students' IT application ability is an urgent problem for teachers to solve. So the common application of combination of IT and OR courses in China can be divided into three categories, from easy to difficult, namely simple application of modelling software, advanced application of office software and application of Numpy based on Python.

\subsection{Simple Application of Modelling Software}

These experiment courses are often combined to the OR theory course. The modelling software commonly used includes Lingo, Lindo, Win QSB and Management Operations Research 3.0 which are designed and developed by a professor of university in China. Such software, which can be used easily, is a simple tool for students to analyze operations research problem. So related experiment courses are often designed like OR experiment, or modelling and optimization experiment. The main contents of these experiment includes linear programming, transportation problem, integer programming, goal programming, dynamic programming, graph theory and queuing theory. As these contents are highly related to OR, these kinds of experiment provides students to solve more complex OR problems which involves more variables and conditions, and students also would like to study these tools which can free them from the tedious calculation process.

Nevertheless, such kinds of experiment courses are limited for the improvement of students' IT application abilities for three reasons. Firstly, these tools are very strict for certain application of OR models, and thus are lack of flexibility for revised OR model. Secondly, the design of such experiments are mainly considered for solving specific problems, and students are not required to construct model for practical problems either from their daily lives or professional issues in their study. Thirdly, students' comprehensive ability are not trained from such relatively simple experiment requirement.

\subsection{Advanced Application of Office Software}

The advanced application of office software in university teaching are commonly know as the application of Microsoft Office or WPS. In the fields of quantitative analysis, MS Office Excel are used widely. From the powerful functions of such software, students can be confident for future study because they are familiar to the basic functions of such software, and thus decrease the difficulty of technology acceptance for these software.

Although these experiments of advanced application of office software can be very practical for students' future work, the comprehensive and flexible application is also limited to a certain space. If the students want to do more difficult research, the students would find such functions of office software are not satisfied any more.

\subsection{Application of Numpy Based on Python}

The ability training of programming language is not required in many business school, however, when considering the importance of technical support for their future development, programming course is necessary. The programming course related to python is the most popular. When mastering required knowledge of Python or C language, students can use tools such as Numpy to solve more complex and practical problems. As such tools are know as open source, the students can solve more academic and realistic problems without obstacles of technology.

However, the application of such tools are not easy for students be familiar with. Many business school students are resistant to IT related courses, even tough they have already studied basic programming courses, it is difficult for students to apply what they have learned flexibly.

If we can combine OR and IT courses in an efficient way for business students, It is obvious that many of their skills can be improved. "New business studies" provide us a creative way to make business students spend more time in studying technology courses, and thus meet the need of their future career development. Shown as fig2., the combined courses system can improve many skills related to IT and quantitative analysis, which are all the core skills of "new business studies".

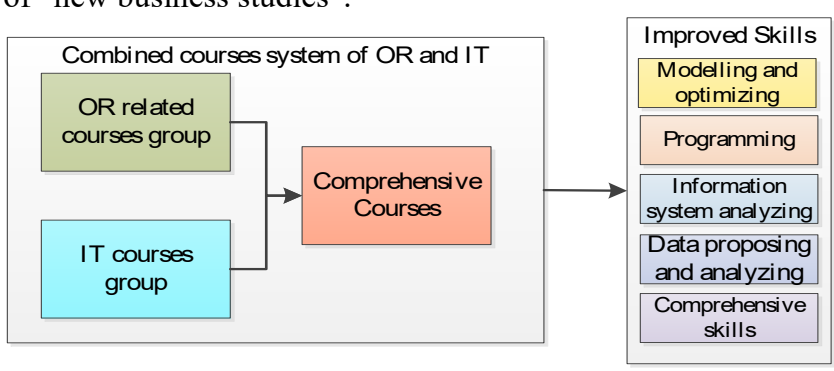

Figure 2 Combined courses system and its improved skills

\section{CASE STUDY}

In order to understand the key points for the success of OR courses systems and IT courses. We use the Guizhou University of Commerce (GUC) as case study object to research the teaching practice of OR courses system and combined courses. We sent out 50 questionnaires named "Design of Business School OR courses system" for economics and management related college teachers, and 200 questionnaires named "A survey on the satisfaction of OR and IT combined courses teaching" for business school undergraduate students and graduates. Combined with survey results, we will discuss the teaching practice of OR course systems and its related IT courses. 


\subsection{The structure of IT and OR combined courses system}

The general structure of IT and OR combined courses system can be shown below as Table 1 .

Table 1 The structure and curriculum of IT and OR combined courses system

\begin{tabular}{|l|l|l|l|}
\hline Semester & Course & Credit & Form \\
\hline First Year I & Advanced Mathematics I & 4 & Required Course \\
\hline First Year I & Basic Application of Computer & 4 & Electives \\
\hline First Year II & Advanced Mathematics II & 4 & Required Course \\
\hline First Year II & Python Programming Base & 4 & Required Course \\
\hline Second Year I & Linear Algebra & 3 & Required Course \\
\hline Second Year II & Probability and Mathematical Statistics & 3 & Required Course \\
\hline Second Year II & Operations Research & 4 & Required Course \\
\hline Second Year II & Experiment of Statistics & 1 & Required Experiment \\
\hline Second Year II & $\begin{array}{l}\text { Experiment of Modelling and } \\
\text { Optimization }\end{array}$ & 1 & Required Experiment \\
\hline Third Year I & Management Information Systems & 3 & Required Course \\
\hline Third Year I & Introductions to Database & 2 & Required Course \\
\hline Third Year I & Experiment of Information System & 1 & Required Experiment \\
\hline Third Year II & Application of Big Data & 2 & Electives \\
\hline Third Year II & Introduction to Data Mining & 2 & Electives \\
\hline Third Year II & $\begin{array}{l}\text { Comprehensive Experiment of Computer } \\
\text { Application in Economics and } \\
\text { Management }\end{array}$ & 2 & \\
\hline Forth Year I & Introduction to Artificial Intelligence & 2 & Requeriment \\
\hline Forth Year I & Crawler Programming base on Python & 2 & Electives \\
\hline Forth Year I & Application of big data & 2 & Electives \\
\hline Forth Year II & Graduation Practice & 8 & Electives \\
\hline Forth Year II & Dissertation Experiment & \\
\hline
\end{tabular}

From Table1, we can see the general structure of OR and IT combined course system in business school undergraduates learning. For students whose major is focused on Economics and Management. The basic ability of combined IT and OR is necessary for two main reasons: First, traditional business school students' career is becoming more and more challenging if they do not follow the new era of AI and big data. The common work such as accountant and seller can be totally replaced by AI information systems. So students should spend more time on learning application of IT related courses to improve their own competitive power.

Second, OR related courses provide important fundamentals for IT related courses. From OR courses, students can improve their logical thinking ability, modelling ability, and ability of algorithm design and optimization. Although students from business school cannot focus on IT course, the improvement of IT applying ability is vital for students to enter higher education and obtain employment.

\subsection{Teaching effect discussion}

From partial survey results, we will discuss the teaching effect of OR and IT combined courses system from the perspective of students and teachers. Most questions of the survey are designed under the form of Likert scale. According to statistical analysis the survey results illustrate some interesting point:

From the survey on the satisfaction of OR and IT combined courses teaching, over $85 \%$ of the students at GUC, who have studied the OR and IT combined courses, feel satisfactory or very satisfactory about this structure , shown as Fig.3. This result demonstrate that students have already realized the importance of IT application and quantitative analysis, and thus would like to spend more time on learning related courses, even for students whose high school background is liberal arts, also think that IT and OR skills are very important. 


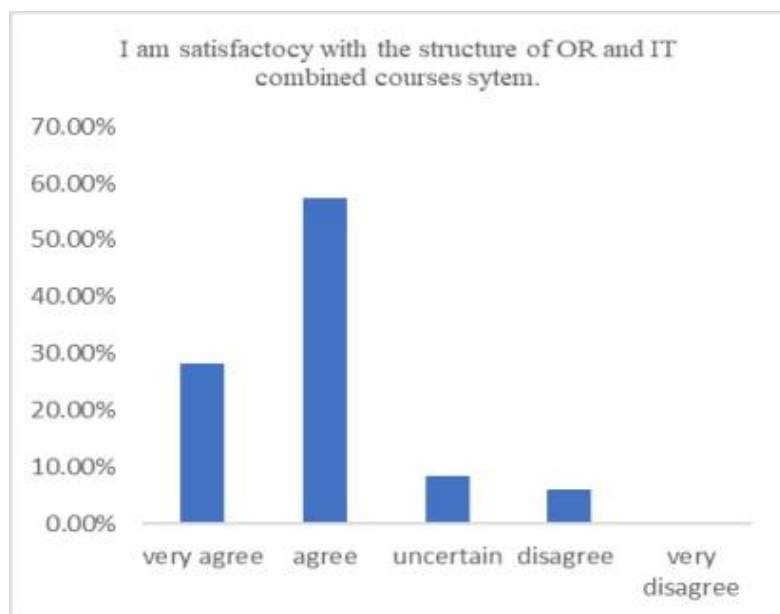

Figure 3 Satisfaction of courses system

Over $75 \%$ of the students agree or very agree that this courses system improve their IT and OR skills, shown as Fig.4.. The result shows that the general design of the IT and OR combined courses system is effective. For students that do not agree this hypothesis, the main reason is that some of these courses are too difficult for them to keep up with.

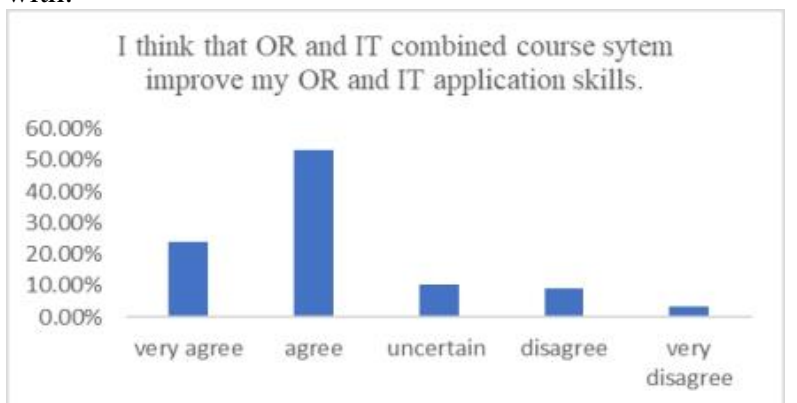

Figure 4 Improvement of skills by IT and OR course system

Over $80 \%$ of the students feel that this courses system is very helpful for their future career development, shown as Fig. 5. This result shows that many students realize that mastering some IT and OR skills may be key point to make them competent for more challenging work rather than traditional office work.

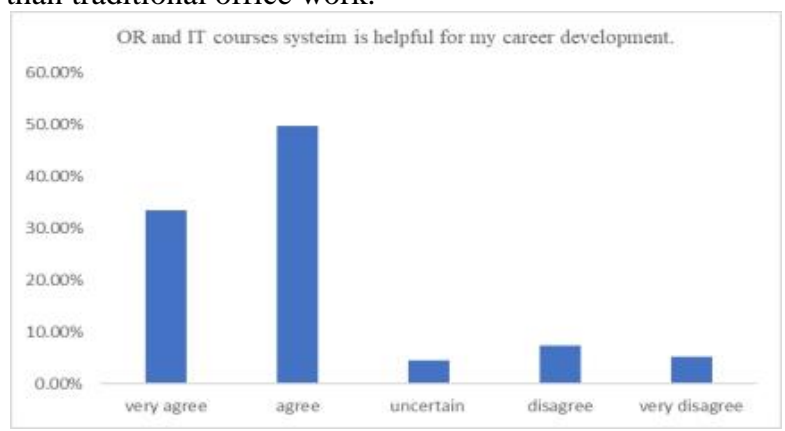

Figure 5 OR and IT combined courses system for career development
However, only nearly $50 \%$ students agree or very agree that OR and IT combined courses meet all their requirement shown as Fig. 6. It is obvious that the courses is various enough but not deep enough, many of them are the type of introduction. Considering the limits of total credits, students should determine their career development direction and them choice deeper continuous courses related to mathematics or computer science.

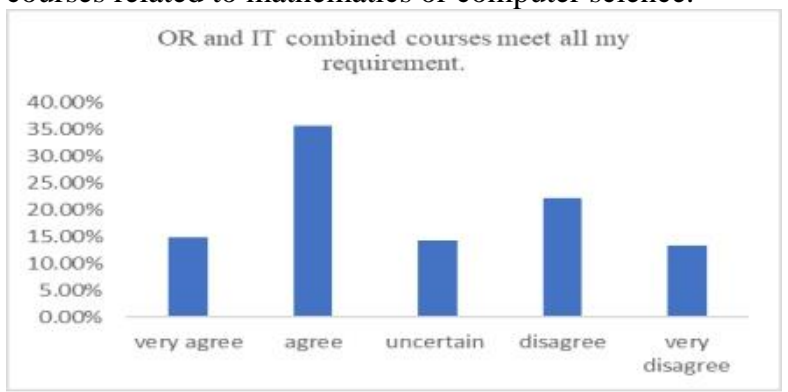

Figure 6 Meeting Requirement of OR and IT combined courses system

From results of survey on "Design of Business School OR courses system", over $70 \%$ teachers agree that OR courses should combine with IT courses, shown as Fig7.. This result also demonstrates that OR and IT combined courses system, compared to independent OR course system, can be for helpful for students' future development.

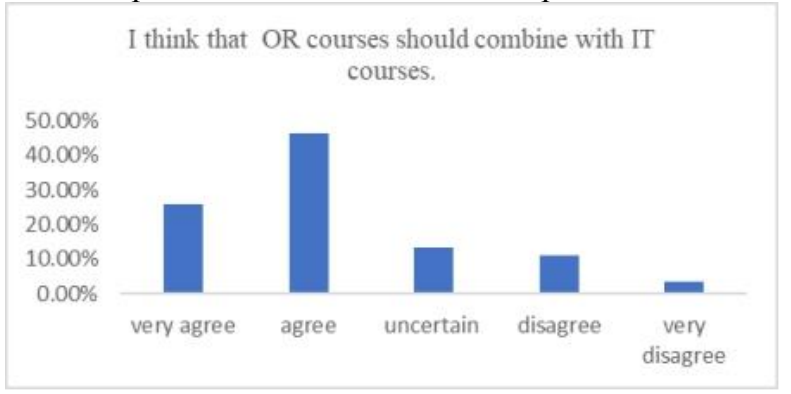

Figure 7 Necessity of combining OR and IT courses

\subsection{Discussion of teaching practice}

As all these survey results show, the revolution of traditional OR courses is necessary for teachers to meet the requirement of new era. Obviously, traditional students from business school should update their curriculum to obtain their competence not only in the field of business itself, but also in IT application and relatively complex quantitative analysis. If business schools realize the importance of technology convergence and interdisciplinary in both business data analysis and IT, more and more business school leaders will consider the combination of OR courses and IT courses.

\section{CONCLUSIONS}

As discussed above, almost all of business schools or commerce universities are faced with challenges from 
different types of recent technologies and the changes of traditional business mode. In addition, these changes give teaching organizations a chance to redesign the curriculum of their traditional course. It is possible to add more IT related types of courses to rich their course structure. Moreover, if we combine OR and IT courses in an initial but efficient way, the effect of teaching practice shows that the business can achieve a new goal that beyond the traditional career limits for students at business school. No matter how difficult for both students and teachers change their traditional curriculum at business school, the revolution of OR and IT combined courses system should be paid more attention.

\section{ACKNOWLEDGMENT}

This work was supported by the teaching content and curriculum system reform project of Guizhou Province under Grant No. 2017520074

\section{REFERENCES}

[1] Hazen, B.T., Skipper, J.B., Boone, C.A. et al. Back in business: operations research in support of big data analytics for operations and supply chain management, Ann Oper Res (2018) 270: 201.

[2] Gupta, Babita; Goul, Michael; and Dinter, Barbara (2015) "Business Intelligence and Big Data in Higher Education: Status of a Multi Year Model Curriculum Development Effort for Business School Undergraduates, MS Graduates, and MBAs,"Communications of the Association for Information Systems: Vol. 36, Article 23.

[3] Larréché, Jean-Claude. On simulations in business education and research $[\mathrm{J}]$. Journal of Business Research, 1987, 15(6):559-571.

[4] Johnes, Jill. Operational Research in education[J]. European Journal of Operational Research, 2015, 243(3):683-696.

[5] Jackson, James R. Letter to the Editor-OperationsResearch Education in Schools of Business. Operations Research, (1959)7(1):131-131.

[6] Erikson, Warren J. Efraim Turban. Teaching operations research on microcomputers[J]. Omega, 1985, 13(3):191-200.

[7] Yang Y., He Y., Zheng S., Wang L. (2014) Study on Teaching Methods of Operations Research. In: Zhong S. (eds) Proceedings of the 2012 International Conference on Cybernetics and Informatics. Lecture Notes in Electrical Engineering, vol 163. Springer, New York, NY
[8] Dias, Joana. Teaching operations research to undergraduate management students: The role of gamification[J]. The International Journal of Management Education, 2017, 15(1):98-111. 